\title{
LifE CYCLE OF NATURAL POPULATIONS OF METRIOCNEMUS (INERMiPUPA) Carmencitabertarum Langton \& Cobo 1997 (Diptera: Chironomidae) in The NeTHERLANDS: INDICATIONS FOR A SOUTHERN ORIGIN?
}

\author{
J.T. Kuper \\ Bargerveen Foundation, Toernooiveld 1, 6525 ED Nijmegen, The Netherlands. \\ Email:j.kuper@science.ru.nl
}

\begin{abstract}
The life-history and behaviour of the chironomid Metriocnemus (Inermipupa) carmencitabertarum was studied for three years and a comparison was made between two populations in the Netherlands. Key life-history characteristics are reported, including the number of generations (2-5 generations) and duration of larval development (19-55 days). Life-history characteristics differed between the two populations and between generations within a population. These differences were likely related to differences in competitors (mainly Chironomus riparius Meigen) and thermal characteristics of the habitat from variations in water volume and ambient temperature. Results suggested a diapause in summer, when water levels dropped, and not in winter. A clear seasonal pattern in body size was found with pupal length increasing steeply at the beginning of the summer. The increase in body size was positively correlated with mean ambient temperature during larval development. This correlation is in contrast with the TemperatureSize Rule (TSR) in ectotherms, which postulates a negative correlation between temperature and adult body size. The chance of ectotherm predators being present in the habitat is low, which may explain this feature. Life history characteristics supported a recent northward range expansion for M. (I.) carmencitabertarum due to warmer winters. If correct, it is predicted that the species will be found in Scotland and northern Germany and/or southern Denmark in the near future.
\end{abstract}

\section{Introduction}

First described from specimens from the northwest of the Iberian peninsula (Langton and Cobo 1997), M. (I.) carmencitabertarum Langton \& Cobo 1997 (Diptera: Chironomidae, subfamily Orthocladiinae) has since then been found on two islands from the Azores archipelago (Murray et al. 2004, Ramos et al. 2010), in England in 2010 (Langton and Wilson 2012), in The Netherlands in 2011 (Kuper \& Moller Pillot 2012), in Ireland in 2012 (Murray 2012) and in Northern Ireland in 2013 (Langton,
2014; Murray et al. 2014). More northern reports of $M$. (I.) carmencitabertarum for Poland and Estonia (Spies and Sæther 2013) and Spitsbergen (Langton and Visser 2003) are probably incorrect, as there are no published records (Murray 2012, eElurikkus 2015) or are not cited in recent lists (Coulson 2014).

Larvae of $M$. (I.) carmencitabertarum were first found in granite rock holes filled with rain water in northwestern Spain (Langton and Cobo 1997). Since then larvae have been reported from similar, yet artificial, water-filled habitats such as animal drinking troughs, rain-filled water butts and buckets in urban surroundings (Murray et al. 2004, Ramos et al. 2010, Langton and Wilson 2012, Kuper \& Moller Pillot 2012, Murray 2012, Murray 2013, Murray 2016). Besides this, little is known about the ecology and life-history. Murray (2013) gives some notes on larval behaviour. Kuper (2015) reported biometric measurements to distinguish the four larval stages and also presented biometric data for pupal exuviae (skins), which revealed a larger average size for females. This sexual size difference was probably already present in fourth instar larvae. The finding of new populations of $M$. (I.) carmencitabertarum in The Netherlands gave the opportunity to collect empirical life history data from two populations during 2012-2014. Here, for the first time, the species' life cycle characteristics are presented and indications for a southern origin of the Dutch populations of M. (I.) carmencitabertarum are discussed.

\section{Material and Methods}

\section{Study sites}

Two populations of $M$. (I.) carmencitabertarum were studied in The Netherlands in 2012 and 2013 to elucidate the species' life cycle. One population was living in a garden bucket in Appingedam $\left(53^{\circ} 19^{\prime} 16.71^{\prime}\right.$ N , 6 51 '41.49” E, Fig. 1). The second population was living in a garden water butt in Nijmegen (51 ${ }^{\circ} 50$ '19.73" N, 5'50'33.58' E, Fig. 1 ). The bucket (capacity of 15 litres) and the water 


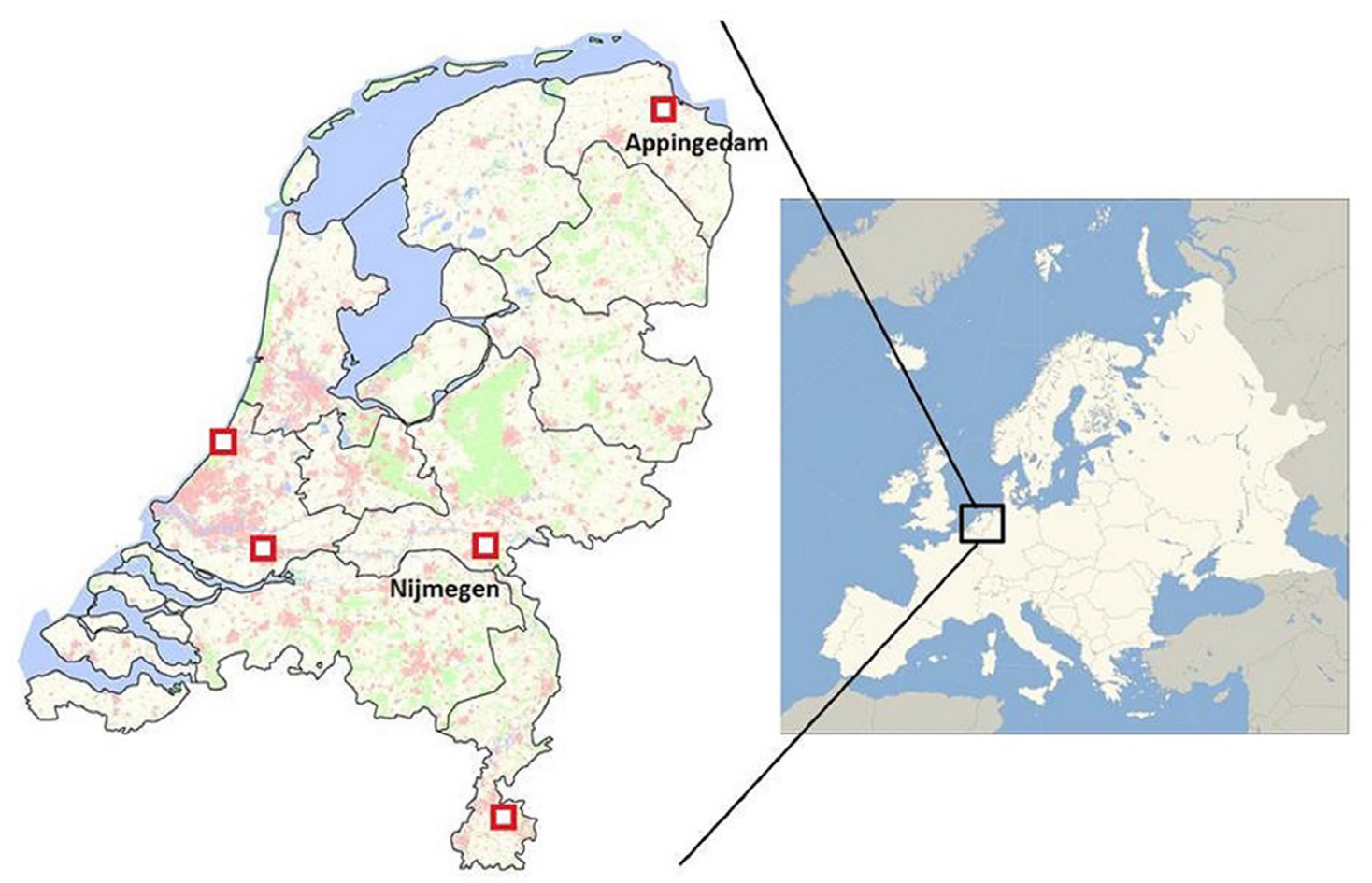

Figure 1. Distribution of Metriocnemus (I.) carmencitabertarum in the Netherlands and the location of the two research sites Appingedam and Nijmegen.

butt (capacity of 200 litres in 2012 and 100 litres in 2013) were located under a roof gutter. During rain showers, rainwater was washed into the bucket and the water butt from the roof. When rain showers were prolonged or heavy water overflowed from the bucket and the water butts. Algae grew on the bottom and along the sides of the bucket and the butts. Much organic debris was present in the bucket. The bucket and the butts never dried up, although water volume and level in the butt declined significantly at the end of August 2012 (at least 75$80 \%$ reduction in water volume) and in July 2013 (at least $60 \%$ reduction), when water was used for gardening purposes. In late spring and summer, the bucket and the butts were sun-exposed until ca. 0900 hrs (CET). During ten days in February 2012, when outdoor maximum temperatures were below $0^{\circ} \mathrm{C}$, the bucket was placed indoors at a temperature of $6-7^{\circ} \mathrm{C}$. During the winter of 2012-2013 the bucket was left outdoors and the water was possibly completely frozen for some time. During the winters of 2011-2012 and 2012-2013, the 200-liter water butt in Nijmegen was partly frozen for some time, with probably a central core of water running down to the base. In April 2013 the 200 litres butt was replaced by a 100 litres butt after the former had burst due to ice formation.

\section{Wintering stages}

To study the wintering stages of M. (I.) carmencitabertarum an outdoor rearing experiment began in June 2013 in Appingedam in a glass vase (capacity of six litres). The vase was closed at the top by a plastic lid with four small holes for air circulation. The lid was placed to keep adults inside for continuous reproduction and to exclude other fauna. The distance between the water layer and the lid was 20-25 cm's, depending on the water level. Some organic debris was added. On 7 July, 2013 algal growth was observed along the sides of the vase and on the organic debris. Then, one egg string was collected from the bucket and placed in the vase. On 9 February, 2014 the lid was removed from the vase to give emerging adults the opportunity to escape.

In late spring and summer, the vase was sun-exposed until ca. 0900 hrs (CET). During the last one and a half weeks of January until 1 February, 2014 an ice layer 10-15 cm thick formed on top and along the sides. A central core of water remained down to the algae and the larvae. Iceformation most probably did not reach the larvae. In this period a layer of snow approximately eight centimetres thick was deposited on top of the lid. The vase was placed in a water-filled bucket to prevent it from bursting. On 2 February 2014, the 
vase was taken out of the bucket, when temperatures stayed above $0{ }^{\circ} \mathrm{C}$. Larvae were sampled with a sieve by up-whirling the debris and algae on the bottom on 29 December 2013 and on 9 February 2014. In December, larvae were sub-sampled and the abundance of the different larval stages was estimated while in February larvae were (probably) completely sampled and counted. After counting, the larvae were replaced in the vase. Sixteen larvae of various sizes were collected and preserved in $70 \%$ ethanol to verify larval stages. Larvae were assigned a larval stage by comparison with the collected individuals. Head width (HW) and head length (HL) of the collected individuals were measured to the nearest $4 \mu \mathrm{m}$ and $10 \mu \mathrm{m}$, depending on the magnification, with a Zeiss microscope at $312.5 x$ and $125 x$ magnification. To assign larval stages, results were plotted in a HW-HL graph of $1^{\text {st }}$ to $4^{\text {th }}$ instar larvae, obtained from Kuper (2015).

On 21 December 2013, the Appingedam bucket was also examined for wintering larvae that were collected and scanned under a Wild M3B stereomicroscope at $64 \mathrm{x}$ magnification. Following examination all larvae, the original water and the debris were replaced in the bucket.

\section{Life cycle data collection}

Observation period. In Appingedam, the population living in the bucket was observed from 24 March 2012 until 1 December 2013. In 2012 observations were interrupted from 29 May until 15 June and from 30 June until 14 July. In 2013 no observations were made from 21 July until 9 August and from 15 September until 26 September.

The population in Nijmegen was studied from 22 May 2012 (when it was discovered) until 20 September 2013, when the water butt was removed and observations had to be stopped. Observations were interrupted in 2012 from 23 May until 17 June, from 1 July until 16 July, and from 21 September until 29 September. In 2013 no observations were made between 22 July and 10 August.

\section{Daily observations}

Data collection at Appingedam and Nijmegen in 2012 consisted of establishing the daily number of adults and number of egg masses, whereas in 2013 pupal exuviae were also collected. In 2013 larval activity was also observed in Nijmegen.

In Appingedam, midge activity was primarily observed on weekend days. During observation days, the bucket was regularly visited, starting at ca. 0800-0900 hrs (CET) until sunset. In 2012 observations were made on average during 3.1 days per week. In 2013, observations were made during 5.2 days per week on average until the second week of June. Then observation frequency decreased to 2.7 days per week. In Nijmegen, observations were mostly carried out during working days, once per day after ca. 1800 hrs (CET). In 2012 observations were made on average during 2.3 days per week and during 4.9 days per week in 2013.

Adults. At Appingedam the largest number of adults that were seen within a radius of ca. 4 metres of the bucket during one observation period represented daily number of adult midges. At Nijmegen the daily number of adults was established once after 1800 hrs (CET), by counting the number of adults inside the water butt and on the wall of the adjacent shed. A flash light was used when it was dark. The observed number of adults probably did not reflect rate of emergence perfectly as individuals could fly away to and arrive from the environment. Therefore pupal exuviae were collected in 2013.

Egg strings. The number of egg strings in Appingedam and Nijmegen were counted around sunset or later. A flash light was used when it was dark.

Larvae. In Nijmegen larvae were counted well after sunset. A flashlight was used to shine at the inner sides of the water butt to reveal larval activity. Larvae could be observed down to ca. 50 $\mathrm{cm}$ 's beneath the water surface. Larvae were either judged to be "large" or "small". Large larvae were presumed to be fourth (possibly third) instar, small larvae were presumed to be younger than fourth instar. Larvae were not collected to verify the categories.

Pupal exuviae. In the Appingedam bucket, pupal exuviae were sampled from the beginning of July in 2013. In Nijmegen exuviae were collected throughout the adult activity period in 2013. The exuviae were collected around sunset or later, or before $1000 \mathrm{hrs}$ (CET) the next day by sieving the water surface with a small net. Exuviae that were attached to the sides of the butt or bucket were removed by tweezers. Pupal exuviae from the wintering population in the Appingedam vase were sampled daily in April and May in 2014. Exuviae were stored in $70 \%$ alcohol for counting, sexing and measuring the length to the nearest $0.1 \mathrm{~mm}$ as the distance from the top of the frontal apotome to the tip of the anal lobe, at 10x magnification (Nikon SMZ645 stereo-microscope).

\section{Generation development time}

The emergence period of a generation was defined by the observed peak in adult activity (number of 
adults, number of egg strings laid, number of pupal exuviae) between periods of lower activity. Generation development time was considered to be the number of days between two consecutive peaks of adult numbers or, if peaks were in a period without observations, by the number of days between date of first adult activity at the start of an activity period and the date of first adult activity at the start of the next activity period.

\section{Temperature data}

If not stated otherwise, all ambient temperature data for 2012-2014 were obtained from AccuWeather.com (2012-2014). Daily temperatures only differed in detail between Appingedam and Nijmegen in 2012 and 2013.

\section{Statistics}

To test if ambient temperature and pupal exuviae size were correlated it was assumed that development time for each exuviae of a generation was the same as was calculated for the generation it belonged to. Then, for each exuviae the mean ambient temperature during development was calculated by averaging daily temperatures of the number of development days prior to the date of emergence. Daily temperature was taken as the mean of minimum and maximum temperature of that day. Correlation between mean ambient temperatures during development and skin size, was tested with the model 'mean ambient temperature during development * skin size with sexes distinguished' in an ANOVA, with mean temperature as a second order polynomial. Analyses were performed in R statistics version 3.0.1 (R-Core-Team, 2013) with standard packages.

\section{Results}

\section{Wintering population}

On 29 December 2013, 40 to 50 larvae were sampled from the Appingedam glass vase and assigned larval stages. Approximately $40-50 \%$ were $3^{\text {rd }}$ and approx. 50-60\% were $4^{\text {th }}$ instar. On 9 February, 34 larvae $(32.1 \%)$ were in $3^{\text {rd }}$ and 72 larvae $(67.9 \%)$ were in $4^{\text {th }}$ larval stage (Fig. 2). Larvae were free living. Larvae of other species were not found. From the beginning of April until the end of May, adults from the wintering population in the vase emerged over a period of almost two months (Fig. $3)$. The emergence pattern followed a 'normally' distributed curve over time.

Larvae of $M$.(I.) carmencitabertarum were not found in the bucket in Appingedam in December

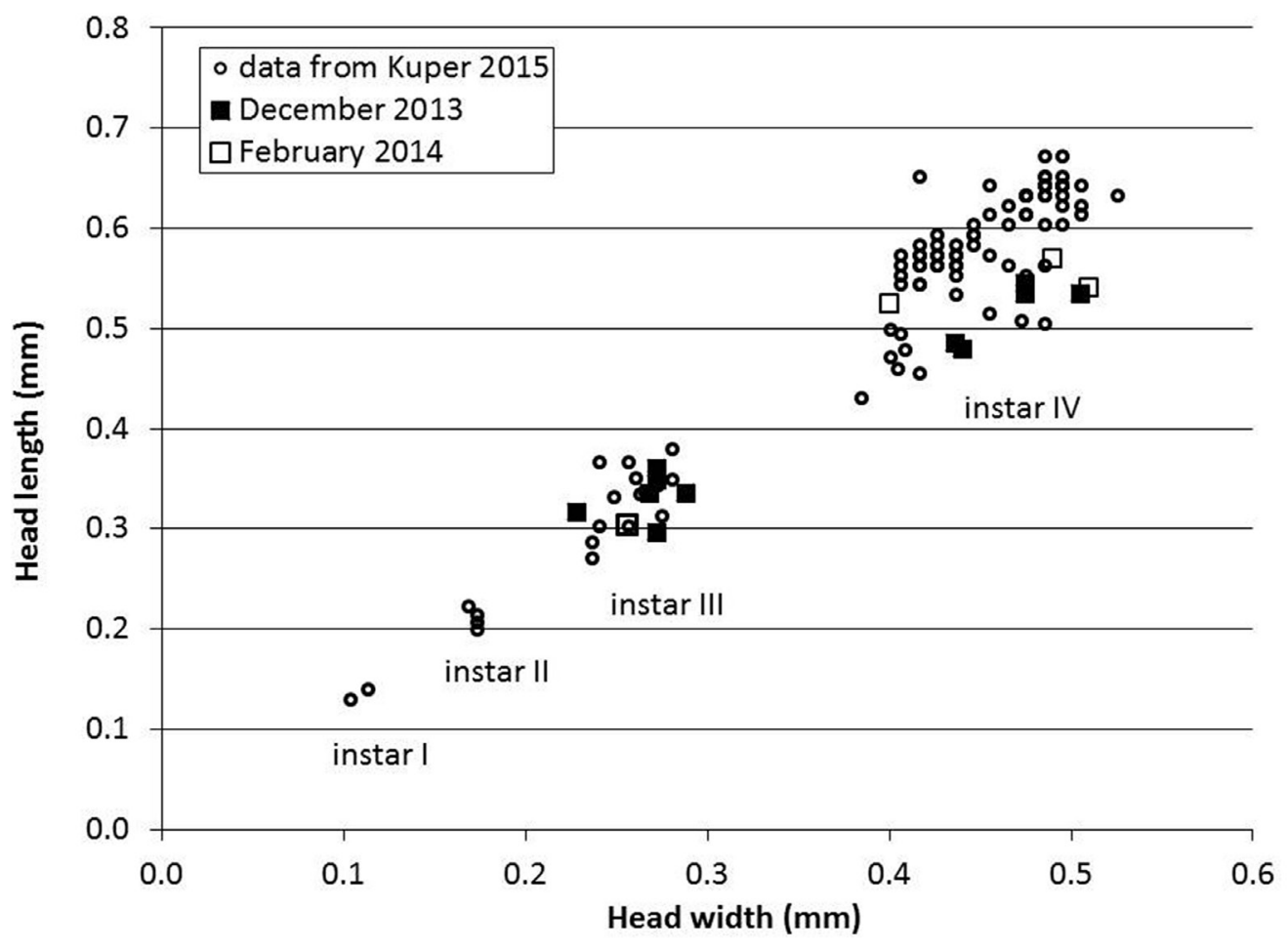

Figure 2. Head width and head length of wintering larvae collected in the Appingedam vase in December 2013 and February 2014. Results are projected in a HW-HL graph of the four M. (I.) carmencitabertarum instars obtained from Kuper (2015) revealing wintering in $3^{\text {rd }}$ and $4^{\text {th }}$ larval stage in the Appingedam vase. 


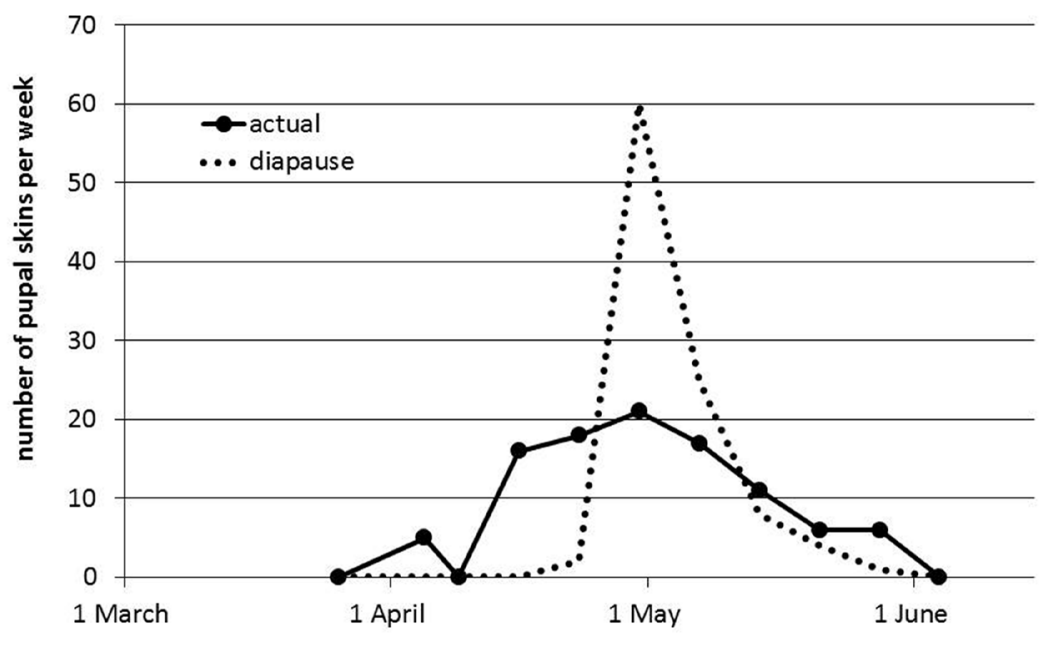

Figure 3. Emergence pattern of the wintering generation from the Appingedam vase in spring 2014 (black dots and solid line) and hypothetical emergence pattern when larval development would have been interrupted by a diapause (dotted line). Number of pupal exuviae are added up per week.

2013. On the other hand, $1214^{\text {th }}$ instar and $63^{\text {rd }}$ and/or $2^{\text {nd }}$ instar larvae of Chironomus riparius (Chironomidae, subfamily Chironominae) were counted, as well as $124^{\text {th }}$ instar larvae of Zavrelimyia sp. (Chironomidae, subfamily Tanypodinae). Larvae of $M$. carmencitabertarum were also not found in an earlier study in December 2011 when larvae of $C$. riparius and Zavrelimyia sp. were also present (Kuper \& Moller Pillot 2012). From May until October 2013, at least three generations of $C$. riparius emerged. A total of 413 pupal exuviae were collected, exceeding the $39 \mathrm{M}$. (I.) carmencitabertarum pupal exuviae by far.

\section{Phenology}

Data on adult activity in 2012 and 2013 in Appingedam and Nijmegen and of larval activity in 2013 in Nijmegen are presented in Fig. 4. The initial and final records of adult activity differed between years and between sites. The number of adult activity peaks, representing emergence of different generations, differed between sites, giving two or perhaps three generations per year in Appingedam (Fig. 4 A, B) and five generations in Nijmegen (Fig. 4 C, D), including the wintering generations that emerged in spring.

In Appingedam the first adult activity in 2012 was observed on 28 April, whereas in the following year it was three weeks later, on 18 May 2013. The final record of adult activity in 2012 was on 17 November, the same date as in 2011 (Kuper \& Moller Pillot 2012). In 2013 however the final record of adult activity was on 7 September, more than two months earlier than other years. Records of adult $M$. (I.) carmencitabertarum in the spring of both years, followed by a period of no activity, probably depicts the emergence of the wintering generation. These individuals must have originated from the neighbourhood, as larvae did not winter in the bucket. After that, no well-defined peaks of adult activity were seen in 2012, which made it impossible to distinguish generations. In 2013 a continuous period of emerging adults (by means of the presence of pupal exuviae) was evident from the beginning of July up and until the first week of September. This might reflect a long period of adults emerging from the eggs that were deposited in spring. Then two generations would have been present in 2013. Yet, within the three weeks observation gap around the beginning of August, a period of no emergence might have occurred, which then would suggest the presence of an additional generation in August. Then three generations, including the wintering generation, emerged.

In Nijmegen the first adult activity in 2012 was observed on 22 May, when the wintering generation was presumably at peak of emergence, indicated by the finding of 30 adults, 20 egg strings, one pupal skin and one pupa. The final adult activity in 2012 was recorded on 2 October, one and a half months earlier than in Appingedam. This could not be linked with ambient temperature differences between the two sites. In 2013, the first observation of adult activity was on 10 June, when the first summer generation emerged. No wintering larvae were present in the butt as it was newly placed in 

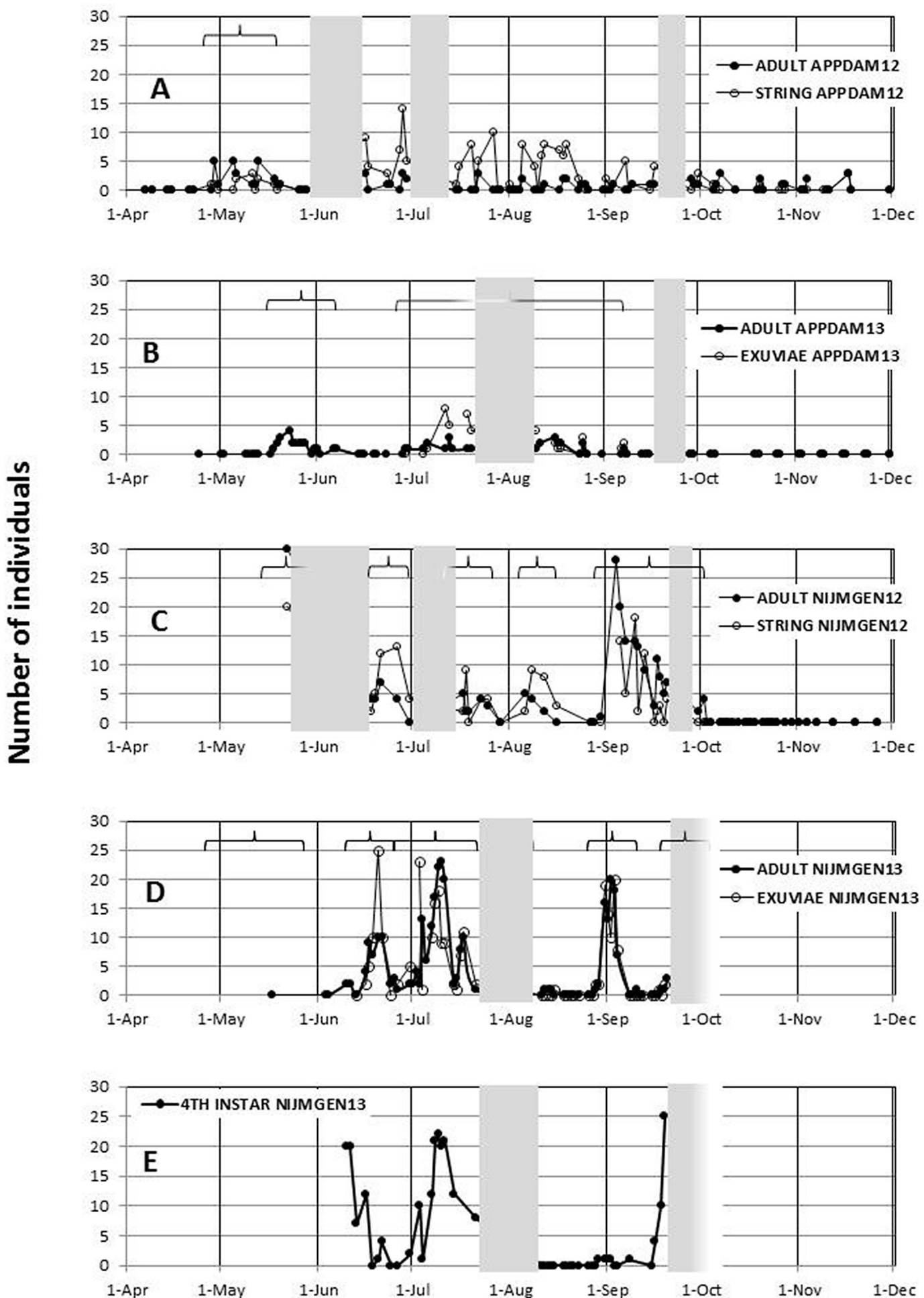

Figure 4 A-E. Numbers of adults, egg strings and pupal exuviae of Metriocnemus (Inermipupa) carmencitabetarum recorded between April and December in 2012 and 2013 at Appingdam and Nijmegen and of 4th instar larvae at Nijmegen in 2013: 4A number of adults and egg strings at Appingedam, 2012; 4B number of adults and pupal exuviae at Appingedam 2013; 4C number of adults and egg strings at Nijmegen 2012; 4D number of adults and pupal exuviae at Nijmegen 2013; 4E numbers of 4th instar larvae recorded in the upper $50 \mathrm{~cm}$ of the water butt at Nijmegen, 2013. Horizontal brackets indicate periods of adult activity of one generation. Periods with no observations are shaded. 
April. Egg deposition by the wintering generation (which must have emerged elsewhere in the neighbourhood), presumably in May, was missed. The final observation was on 20 September, after which the butt was removed and observations had to be ended. No other chironomid species were found in Nijmegen, except from the middle of September 2013 when C. riparius started to emerge.

The population in Nijmegen showed well-defined peaks of activity in 2012 and 2013, indicating emergences of consecutive generations. The start of the last emergence bout on 19 and 20 September 2013 was abruptly interrupted by the removal of the butt. This emergence bout was accompanied by a steep increase of fourth instar larvae moving up to the top of the butt as was also seen during the emergence of adults in June and July 2013 (Fig. 4 E). Thus, in both years five generations (including the wintering generation) emerged from May until September. From 11 August 2013 onwards, a two and a half week period with no larval and hardly any adult activity was observed. In the second half of July up to and including the first week of August, 2013, water volume in the butt decreased by at least $60 \%$ as water was used for gardening purposes. Observations re-commenced on $11 \mathrm{Au}-$ gust when the butt was filled again with rain water. At the end of August the adults of this generation emerged in a time frame of seven to ten days, with the majority emerging in a period of just four days. This emergence was not accompanied by $4^{\text {th }}$ instar larval activity along the sides of the butt. In June, July and September $4^{\text {th }}$ instar larval activity was at its peak during or just before emergence.

\section{Generation development time}

At Appingedam the development time of the (first) summer generation was between 31 and 49 days in 2012. An exact number of days cannot be given because the first activity of the summer generation probably took place in a period when no observations were made and a clear activity peak was not observed (Table 1, Fig. 4 A). In 2013 the development time of the (first) summer generation was 42 days (Table 1, Fig. 4 B). At Nijmegen in 2012, the development time of summer generations ranged from 21 days for the third summer generation in August to ca. 30 days for the first summer generation in June (Table 1, Fig. 4 C). In 2013 the development time ranged from 19 days for the second summer generation in July up to 55 days for the third summer generation at the end of August (Table 1, Fig. 4 D). The latter included a diapause of at least two and a half weeks (see Phenology). The overall, mean development time for a generation in the summer period in Nijmegen (excluding the generation that probably had a diapause) was 24.2 \pm 4.4 days.

\section{Seasonal length differences in pupal exuviae}

A seasonal difference in length of male and female pupal exuviae was observed in the Nijmegen population during the summer of 2013 (Fig. 5), with a sharp increase of pupal skin size at the beginning of the summer. The model 'mean ambient temperature during development $*$ skin size with sexes distinguished' tested highly significant (ANOVA, $\left.\mathrm{R}^{2}=0.74, \mathrm{p}<0.001\right)$. Pupal skin size of males increased clearly less markedly with increasing mean temperature during development compared to those of females (Fig. 6).

\section{Discussion}

\section{Phenology}

In Appingedam, over-wintering larvae were absent and were not found in two thorough searches in December 2011 and 2013. Adults from the neighbourhood recolonised the bucket each spring. The

Table 1. Generation development time in days. The generation concerned is denoted after the arrow under 'generation'. DT is development time of a generation. For Appingedam 2012 only a minimum and maximum for DT could be given.

\begin{tabular}{lllll}
\hline Site and year & Generation & Measuring point & Period & DT (days) \\
\hline Appingedam 2012 & winter $\rightarrow$ st & first adults & 28 Apr - 29 May & 31 (min) \\
& winter $\rightarrow 1$ st & first adults & 28 Apr - 16 Jun & $49(\operatorname{max)}$ \\
Appingedam 2013 & winter $\rightarrow$ st & first adults & 18 May - 29 Jun & 42 \\
Nijmegen 2012 & winter $\rightarrow$ st & peak adults & $\sim 22 \mathrm{May}$ - 21 Jun & $\sim 30$ \\
& 1st $\rightarrow$ nd & peak adults & 21 Jun - 18 Jul & 27 \\
& 2nd $\rightarrow$ 3rd & peak adults & 18 Jul - 8 Aug & 21 \\
Nijmegen 2013 & 3rd $\rightarrow$ 4th & peak adults & 8 Aug - 4 Sep & 27 \\
& 1st $\rightarrow$ 2nd & peak adults & 20 Jun - 9 Jul & 19 \\
& 2nd $\rightarrow$ 3rd & peak adults & 9 Jul - 2 Sep & 55 (diapause) \\
& 3rd $\rightarrow$ 4th & first adults & 28 Aug - 18 Sep & 21 \\
\hline
\end{tabular}




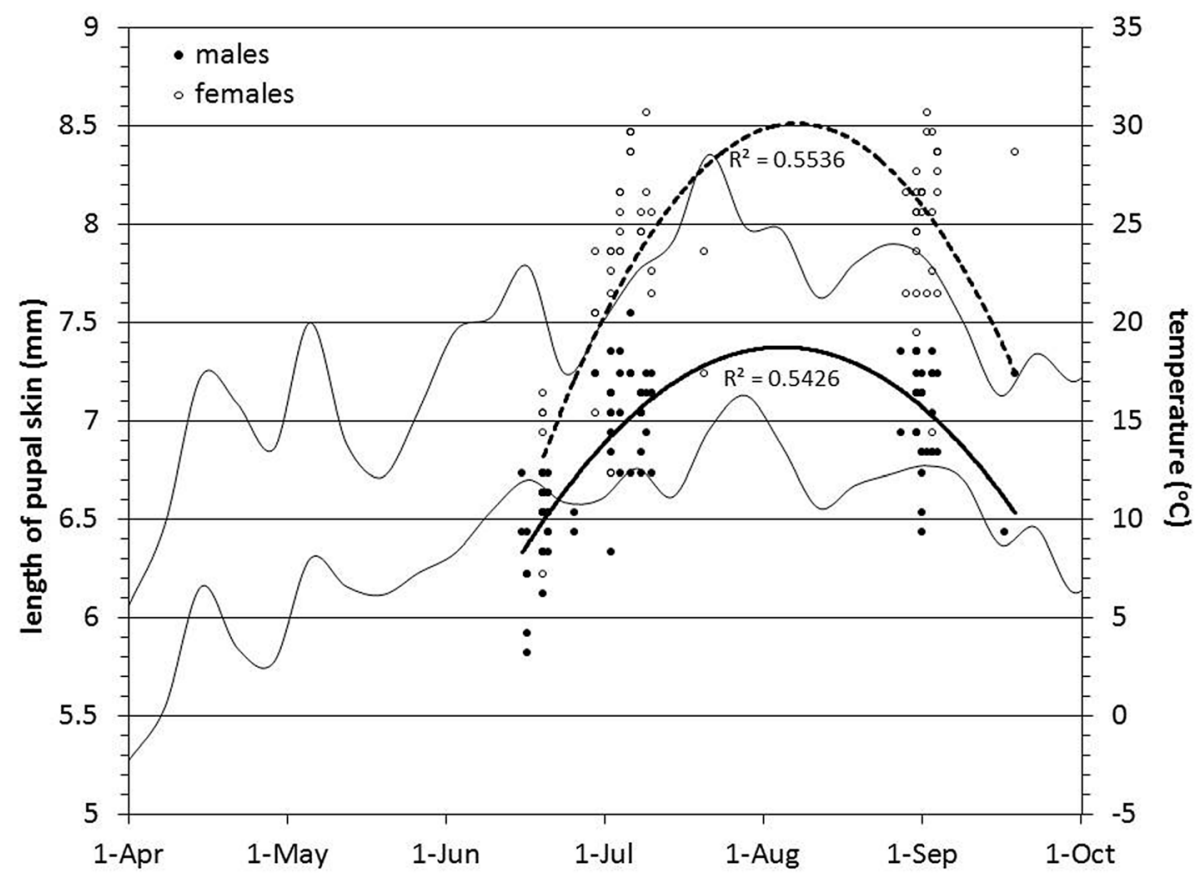

Figure 5. Seasonal length differences in male and female pupal exuviae in Nijmegen in 2013, with a binomial fit (left $\mathrm{y}$-axis). The two wavy lines represent mean weekly minimum and maximum temperatures from April to October (right y-axis).

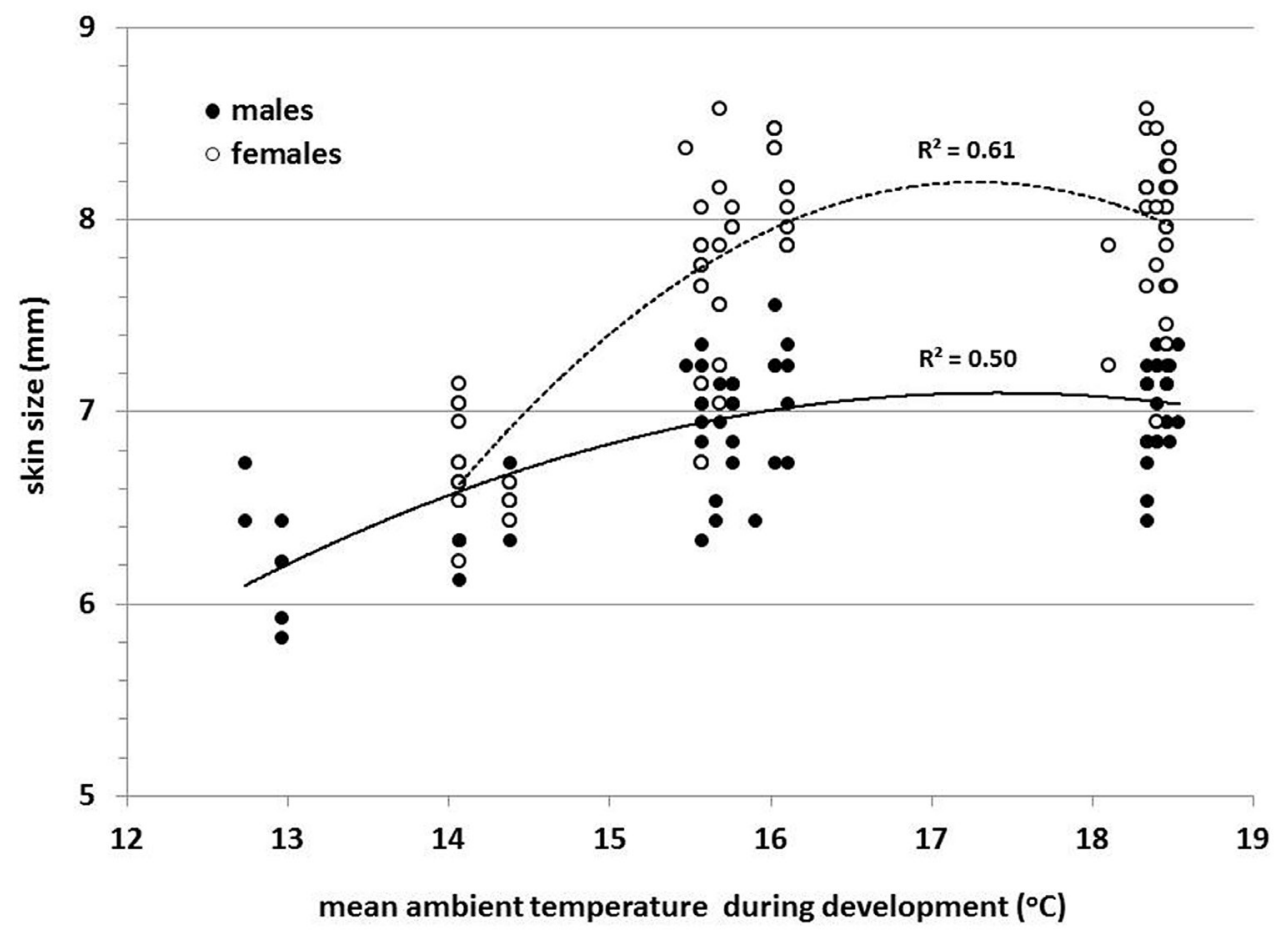

Figure 6. Correlation between mean ambient temperature during development and skin size for males and females from the Nijmegen water butt in 2013. 
first observations of adult activity in 2012 were made at the end of April and three weeks later in 2013, in the middle of May. This three week difference is most probably caused by a colder period from the midst of February until the end of March in 2013 compared to 2012. The first observations of emergence of the wintering generation in 2012 in Nijmegen were made on May 22, which was presumably a peak in emergence following the onset of emergences around the middle of May. This was about two to three weeks later compared to first observations of adults in Appingedam in 2012. As the volume of the water butt was large (200 litres) it is possible that temperature in the butt was increasing more slowly than in the unknown habitat of the wintering population(s) in Appingedam in late winter and spring. The rate of development of chironomid larvae generally increases with increasing ambient temperatures (e.g. Mackey 1977, Pinder 1986). Differences in winter/ spring temperatures and differences in the warming up rate of the larval habitat might thus explain observed differences in timing of emergence of the wintering populations between years and between habitats.

The final records of adult activity differed markedly between years in Appingedam and between Appingedam and Nijmegen. As autumn temperatures did not differ much between years and between both sites, factors other than temperature determined the end of adult activity.

In Ireland, M. (I.) carmencitabertarum adults were active from the end of March until the middle of November in 2012 and from the middle of April until at least the end of October in 2013 (Murray 2013). The earlier onset of emergence compared to The Netherlands is probably due to the more temperate winter in Ireland compared to The Netherlands, as minimum temperatures rarely reach values below zero degrees Celsius, in contrast to the Netherlands. The earlier start of the adult activity period in 2012 was probably influenced by a warmer winter compared to 2013, as was the case in the Netherlands.

\section{Diapause}

Results suggested that larvae of $M$. (I.) carmencitabertarum did not have a winter diapause. Spring emergence of adults from the wintering population was not synchronized but had a Gaussian distribution shape (Fig. 3). Emergence took place over a period of almost two months. For a winter diapause, a shorter and skewed period of emergence, as depicted in Fig. 3, would have been expected, because most (or all) larvae would be in a dis- tinct developmental stage during winter (Goddeeris 1983, Goddeeris 1986). Also, the presence of only $3^{\text {rd }}$ and $4^{\text {th }}$ instar larvae, with the latter in a small majority in December 2013, suggested that larvae were not in diapause. Many species have a diapause in the $2^{\text {nd }}$ to $4^{\text {th }}$ instar (Grodhaus 1980, Goddeeris 1983). In several Psectrocladius spp. an accumulation of $2^{\text {nd }}$ and $3^{\text {rd }}$ instars with almost no $4^{\text {th }}$ instars was found in autumn while one Psectrocladius sp. was found in early $4^{\text {th }}$ instar only. These finds suggested a diapause triggered by the shortening of days in autumn (Goddeeris 1983, Goddeeris 1986, Moller Pillot 2013). Goddeeris in Moller Pillot (2013) states that the $3^{\text {rd }}$ larval stage would be the most appropriate for a winter diapause.

A long period of inactivity in August 2013 in the Nijmegen butt, followed by a sudden and short high-peaked emergence of adults, suggested a summer diapause. Emergence peaked in a period of only four days. No ( $4^{\text {th }}$ instar) larvae were observed just before or simultaneously with the emergence period which was in contrast with emergence periods in June, July and September. This diapause might have been triggered by a large decrease in water volume in the butt at the end of July, possibly in combination with high temperatures. To avoid disturbance, no butt bottom samples were taken. Therefore, although diapause was not actually confirmed, it seems the most probable explanation for these observations.

Number of generations and generation development time

At least two generations were noted in Appingedam in 2012 and 2013. In Nijmegen five generations per year were recorded in 2012 and 2013. Exact information about number of generations for other Metriocnemus species in Western Europe is not available but some species can be found all year round, implying that several generations per year will develop (Moller Pillot 2013). Some similar sized Orthocladiinae of stagnant waters, e.g. Psectrocladius spp. and Cricotopus spp. (Moller Pillot 1984), have two to seven generations per year (Moller Pillot 2013).

In Appingedam the development time of a generation in the summer was about 42 days. Without taking the diapause generation into account, average development time per generation in Nijmegen was 24.2 days (19-ca. 30 days) during the summer. For Psectrocladius spp. and Cricotopus spp., development time of a generation is one to four months (Moller Pillot 2013). In P. limbatellus, mass emergence was found 18-20 days after colo- 
nisation of sand filter beds (Wotton et al. 1992). Thus in Nijmegen the summer generations of $M$. (I.) carmencitabertarum developed faster than has generally been found in other Orthocladiinae species of similar size in natural habitats, and is only little longer than was found for the fastest development in P. limbatellus, which probably had close to optimal growing conditions.

The longer development time in Appingedam with only one or two generations in the summer, was probably caused by competition from Chironomus riparius. Larvae of this species were present yearround in the Appingedam bucket, by far exceeding the number of $M$. (I.) carmencitabertarum larvae. In the Nijmegen butt a generation of $C$. riparius larvae was only present in September 2013, but this did not slow down development time of $M$. (I.) carmencitabertarum larvae (table 1). As the Nijmegen butt was much larger than the Appingedam bucket, interspecific competition in the butt was probably low. In general, high (interspecific) competition pressure slows down development rate, thus time for development increases (e.g. Vallenduuk and Moller Pillot 2007, Moller Pillot 2013).

Temperature effect on pupal skin length and the Temperature-Size Rule

A temperature dependent correlation was found for pupal skin length and average temperature during development. According to the temperaturesize rule (TSR) body size in ectotherms decreases with increasing, yet not stressful, temperatures, although exceptions exist (Atkinson 1994, Atkinson 1995). The TSR also applies to chironomids (Eggermont and Heiri 2011), as was shown in several laboratory experiments (e.g. Frouz et al. 2002, Dettinger-Klemm 2003, McKie and Cranston 2005, Baek et al. 2012). A decrease in length with increasing temperatures is the outcome of a more accelerated development rate compared to growth rate (e.g. Mackey 1977).

M. (I.) carmencitabertarum seems to be one of the species to which the TSR does not apply. Atkinson (1995) poses four possible mechanisms to explain exceptions to the TSR. One that seems applicable here, is that if ectotherm predators are present (in aquatic habitats), it would be advantageous for prey species to be small when temperatures increase, because feeding rates of ectotherm predators generally increase with increasing temperatures (Atkinson 1995). In this study ectotherm predators were only present in the Appingedam bucket in the winter as $4^{\text {th }}$ instar Zavrelimyia larvae. Whether these individuals were responsible for $M$. (I.) carmencitabertarum larvae not being present may be questioned. Larvae of Zavrelimyia probably feed on small and less mobile prey species (see Vallenduuk \& Moller Pillot 2007). Up to third instar larvae of $M$. (I.) carmencitabertarum are probably small enough but are quite mobile. Thus M. (I.) carmencitabertarum larvae may not be the preferred prey type for Zavrelimyia larvae. In the small-sized, possibly temporary, habitats of $M$. (I.) carmencitabertarum the chance of ectotherm predators being present, is probably low. Thus for M. (I.) carmencitabertarum there is a low pressure to grow small when temperatures are high to decrease chance of predation.

\section{Northward bound?}

Murray (2013) suggested that M. (I.) carmencitabertarum had recently arrived in Ireland as the species was not present in his extensive 50-years collection from Ireland. Moreover, because the pupal exuviae are very characteristic and easy to identify (see also Murray 2016) and the species is found in anthropogenic habitats, the chance that the species has been overlooked until recently seems very unlikely. Therefore, the recent finds of M. (I.) carmencitabertarum in England and Ireland and in The Netherlands in a short time frame indeed suggest an expansion of the species' range. Could this expansion be from southern origin? There are some indications that this might be the case. More northern reports of M. (I.) carmencitabertarum were not confirmed, indicating that the species is probably not present in Poland and Estonia and certainly not in Spitsbergen. Thus, it does not seem likely that $M$. (I.) carmencitabertarum is migrating from northern or northeastern directions. The species does not have a diapause in winter to overcome freezing conditions nor do the larvae build cocoons when temperatures are near freezing point (see e.g. Oliver 1971, Frouz et al. 2003, Specziár 2008). To the south of The Netherlands winters are milder. For example, winter temperatures in north-western Spain almost never reach sub-zero values, with no freezing up of $M$. (I.) carmencitabertarum habitats. Here, adjustments to overcome low temperatures are therefore not needed. According to Hellmann's formula to describe winter temperatures, twelve winters were 'mild', 'very mild' or 'extraordinary mild' while seven winters were 'average’ after 1997 until 2017 in The Netherlands (KNMI 2017). Although frost periods were present, winters in general were apparently mild enough for $M$. (I.) carmencitabertarum populations to survive since its first discovery in August 2011.

If the conclusion is justified that $M$. (I.) carmen- 
citabertarum has recently shifted its range northwards, then it is predicted that the species will be found in Scotland and in the north of Germany and/or in the south of Denmark in the near future.

\section{Acknowledgements}

I would like to thank the following persons for their kind help: Peter Langton for identifying pupal exuviae of Chironomus riparius. Declan Murray for providing literature and sharing some observations and thoughts by e-mail. Tarmo Timm for checking records of $M$. (I.) carmencitabertarum from Estonia and pointing out the existence of the Estonian biodiversity database eElurikkus. Special thanks to Wilco Verberk for statistical help and valuable comments on an earlier draft of this article and to an anonymous reviewer for improving the content and the English text. Very special thanks to Mrs. Janny Kuper-Damhof $\uparrow$, who collected most of the pupal exuviae in Appingedam.

\section{References}

AccuWeather.com, http://www.accuweather.com/ $\mathrm{nl} / \mathrm{nl} /$ netherlands-weather.

Atkinson, D. 1994. Temperature and organism size - a biological law for ectotherms? - Advances in Ecological Research 25: 1-58.

Atkinson, D. 1995. Effects of temperature on the size of aquatic ectotherms - exceptions to the general rule. - Journal of Thermal Biology 20: $61-74$.

Baek, M.J., Yoon, T.J. and Bae, Y.J. 2012. Development of Glyptotendipes tokunagai (Diptera: Chironomidae) under different temperature conditions. - Environmental Entomology 41 (4): 950- 958. DOI: https://doi.org/10.1603/ EN11286

Coulson, S. 2014. The terrestrial and freshwater invertebrate fauna of Svalbard: a checklist. http://www.unis.no/35 STAFF/staff webpages/biology/steve coulson/documents/Invertdatabase 15-09-14.pdf.

Dettinger-Klemm, P.-M.A. 2003. Chironomids (Diptera, Nematocera) of temporary pools an ecological case study. - PhD-thesis, Phillips University Marburg, Marburg/Lahn. 371 pp.

eElurikkus. 2015. http://elurikkus.ut.ee.

Eggermont, H. and Heiri, O. 2011. The chironomid-temperature relationship: expression in nature and palaeo-environmental implications. - Biological Reviews 87: 430-456. DOI: https:// doi.org/10.1111/j.1469-185X.2011.00206.X
Frouz, J., Ali, A. and Lobinske, R.J. 2002. Influence of temperature on developmental rate, wing length, and larval head capsule size of pestiferous midge Chironomus crassicaudatus (Diptera: Chironomidae). - Journal of Economic Entomology 95(4): 699-705. DOI: https://doi.org/10.1603/0022-0493-95.4.699

Frouz, J., Matena, J. and Ali, A. 2003. Survival strategies of chironomids (Diptera: Chironomidae) living in temporary habitats: a review. - European Journal of Entomology 100(4): 459-465.

Goddeeris, B. 1983. Het soortspecifieke patroon in de jaarcyclus van de Chironomidae (Diptera) in twee visvijvers te Mirwart (Ardennen). PhD-thesis, Katholieke Universiteit Leuven, Leuven. 177 pp. + suppl.

Goddeeris, B. 1986. A Methodology for the study of the life cycle of aquatic Chironomidae (Diptera). - Verh. Symposium Invertebr. België 1989. 379-385.

Grodhaus, G. 1980. Aestivating chironomid larvae associated with vernal pools. In Murray, D.A. (Ed.) Chironomidae: ecology, systematics, cytology and physiology. Oxford, Pergamon Press, pp. 315-322.

KNMI 2017. Hellmann-koudegetallen. - https:// www.knmi.nl/nederland- $\quad$ nu/klimatologie/lijsten/hellmann

Kuper, J.T. 2015. Biometry of larvae and exuviae of Metriocnemus carmencitabertarum Langton \& Cobo 1997 (Diptera: Chironomidae) in The Netherlands. - Lauterbornia 79: 31-36.

Kuper, J.T. and Moller Pillot, H.K.M. 2012. Metriocnemus carmencitabertarum, een nieuwe dansmug voor Nederland (Diptera: Chironomidae). - Nederlandse Faunistische Mededelingen 38: 49-54.

Langton, P. H. 2015. Metriocnemus (Inermipupa) carmencitabertarum Langton and Cobo now in Northern Ireland. - Dipterists Digest 22(1): 10.

Langton, P.H. and Visser, H. 2003. Chironomidae exuviae - A key to pupal exuviae of the West Palaearctic Region (Interactive System for the European Limnofauna Biodiversity). Paris, Centre of ETI, UNESCO Publishing.

Langton, P.H. and Cobo, F. 1997. Metriocnemus (Inermipupa) carmencitabertarum subgen.n., sp. n. (Diptera: Chironomidae) from Spain and Portugal. - Entomologist's Gazette 48: 263271. 
Langton, P.H. and Wilson, R.S. 2012. Metriocnemus (Inermipupa) carmencitabertarum Langton and Cobo, 1997 (Diptera: Chironomidae) in England. - Dipterists Digest 19 (Second Series): 141 .

Mackey, A.P. 1977. Growth and development of larval Chironomidae. - Oikos 28: 270-275.

McKie, B.G. and Cranston, P.S. 2005. Size matters: systematic and ecological implications of allometry in the responses of chironomid midge morphological ratios to experimental temperature manipulations. - Canadian Journal of Zoology 83: 553-568. DOI: https://doi. org/10.1139/Z05-051

Moller Pillot, H.K.M. 1984. De larven der Nederlandse Chironomidae (Diptera) (Orthocladiinae sensu lato). - Nederlandse Faunistische Mededelingen 1B: 1-175.

Moller Pillot, H.K.M. 2013. Chironomidae larvae of the Netherlands and the adjacent lowlands III. Biology and ecology of the aquatic Orthocladiinae. KNNV Publishing, $312 \mathrm{p}$.

Murray, D.A. 2012. First record for Ireland of Metriocnemus (Inermipupa) carmencitabertarum Langton and Cobo, 1997 (Diptera: Chironomidae, Orthocladiinae). - Bulletin of the Irish Biogeographical Society 36: 3-7.

Murray, D.A. 2013. Supplementary records of Metriocnemus (Inermipupa) carmencitabertarum Langton and Cobo, 1997. (Diptera: Chironomidae) in Ireland with some observations on larval behaviour. - Bulletin of the Irish Biogeographical Society 37: 204-207.

Murray, D.A. 2016. A new record of Metriocnemus (Inermipupa) carmencitabertarum (Orthocladiinae) from England. - CHIRONOMUS 29: 43-44. http://www.ntnu.no/ojs/index.php/ chironomus/article/view/2174/2113

Murray, D.A., Hughes, S.J., Furse, M.T., and Murray, W.A. 2004. New records of Chironomidae (Diptera: Insecta) from the Azores, Macaronesia. - International Journal of Limnology 40 (1): 3342. DOI: https://doi.org/10.1051/ $\underline{\operatorname{limn} / 2004004}$
Murray, D. A., Langton, P. H., O'Connor, J. P. and Ashe, P. 2014 - Distribution records of Irish Chironomidae (Diptera): Part 2 - Orthocladiinae. - Bulletin of the Irish Biogeographical Society 38: 61-246.

Oliver, D.R. 1971. Life history of the Chironomidae. - Annual Review of Entomology 16: 211230 .

Pinder, L.C.V. 1986. Biology of freshwater Chironomidae. - Annual Review of Entomology 31: 1-23.

Ramos, J., Raposeiro, P.M., Cunha, A., Silva, A.A., Costa,A.C., and Gonçalves, V. 2010. Chironomidae (Diptera: Insecta) da ilha de Santa Maria. - Relatórios e Comunicações do Departamento de Biologia 36: 97101.

R-Core-Team (2013). R: A language and environment for statistical computing. R Foundation for Statistical Computing, Vienna, Austria.

Spies, M. and Sæther, O.A. 2013. - Fauna Europaea: Chironomidae. Fauna Europaea: Diptera, version 2.6, https://fauna-eu.org/

Specziár, A. 2008. Life history patterns of Procladius choreus, Tanypus punctipennis and Chironomus balatonicus in Lake Balaton. - Annales de Limnologie - International Journal of Limnology 44 (3): 181-188. DOI: http://dx.doi. org/10.1051/limn:2008002

Vallenduuk, H.J. and Moller Pillot, H.K.M. 2007. Chironomidae larvae of the Netherlands and the adjacent lowlands I. General ecology and Tanypodinae. KNNV Publishing, $172 \mathrm{p}$.

Wotton, R.S., P.D. Armitage, K. Aston, J.H. Blackburn, M. Hamburger and C.A. Woodward. 1992. Colonization and emergence of midges (Chironomidae: Diptera) in slow sand filter beds. - Netherlands Journal of Aquatic Ecology 26: 331-339. 